David W. Dowdy

Mark P. Eid

Artyom Sedrakyan

Pedro A. Mendez-Tellez

Peter J. Pronovost

Margaret S. Herridge

Dale M. Needham

\section{Quality of life in adult survivors of critical illness: A systematic review of the literature}

Published online: 11 June 2005

(C) Springer-Verlag 2005

The online version of the original article can be found at http://dx.doi.org/10.1007/s00134-005-2592-6

\section{W. Dowdy}

Department of Epidemiology,

Johns Hopkins Bloomberg School of Public Health,

Baltimore, MD, USA

\section{A. Sedrakyan · P. J. Pronovost}

Department of Health Policy and Management,

Johns Hopkins Bloomberg School of Public Health,

Baltimore, MD, USA

D. W. Dowdy · M. P. Eid

School of Medicine,

Johns Hopkins University,

Baltimore, MD, USA

P. A. Mendez-Tellez · P. J. Pronovost

Department of Anesthesiology \& Critical Care Medicine,

Johns Hopkins University,

Baltimore, MD, USA

P. J. Pronovost

Department of Surgery,

Johns Hopkins University,

Baltimore, MD, USA

D. M. Needham (๘)

Division of Pulmonary \& Critical Care Medicine,

Johns Hopkins University,

1830 E. Monument Street, 5th floor, Baltimore, MD, 21205, USA

e-mail: dale.needham@utoronto.ca

M. S. Herridge

Interdepartmental Division of Critical Care Medicine,

University of Toronto,

Toronto, Ontario, Canada

\section{Intensive Care Med (2005) 31:611-620}

In the section "Description of measurement instruments" on page 612 the last sentence of the first paragraph should have read:

Other instruments, such as the Fernandez questionnaire [16], were excluded because they lacked specific domains or because they were used in $\leq 5$ critical care studies, including studies of specific subpopulations [3]. 